\title{
KONSEP KEPEMIMPINAN PERPUSTAKAAN PERGURUAN TINGGI DI ERA DIGITAL (SEBUAH KAJIAN TERHADAP GAYA KEPEMIMPINAN TRANSFORMASIONAL)
}

\author{
Iskandar ${ }^{1}$, Lubis $^{2}$ \\ Jurusan Ilmu Perpustakaan, Fakultas Ilmu Sosial dan Ilmu Politik \\ Universitas Muhammadiyah Mataram \\ iskandarngali94@gmail.com
}

INFO ARTIKEL
Riwayat Artikel:
Diterima:...-...-...
Disetujui:...-...-...

Kata Kunci:

Digital, Kepemimpinan Transformasional,

Perpustakaan

\section{A. PENDAHULUAN}

Keberadaan perpustakaan perguruan tinggi merupakan bentuk dari kesiapan lembaga pendidikan dalam memberikan jaminan atas terpenuhinya hak informasi bagi para civitas akademika yang ada di perguruan tinggi tersebut. Ledakan informasi yang begitu besar, akibat dari kemajuan teknologi ikut mempengaruhi eksistensi perpustakaan dalam memenuhi kebutuhan informasi penggunannya. Keberadaan teknologi informasi ini telah merubah media penyampaian informasi di perpustakaan, dari printed menjadi paperless, sehingga dapat merubah pola organisasi perpustakaan.

$$
\text { Perubahan organisasi bisa berupa }
$$
perubahan teknologi, struktur, individu dan fisik yang membutuhkan pengetahuan, keterampilan serta budaya baru. Dalam melakukan perubahan terhadap organisassi banyak faktor yang menghambat perubahan tersebut termasuk budaya organisasi yang menolak akan perubahan serta kepemimpinan yang lemah.

Pernyataan tersebut didukung oleh pendapat Daff (1988:659) yang menyatakan bahwa, kepemimpinan dapat mendorong, serta mendukung kreatifitas untuk membantu pengikut dan organisasi agar lebih menerima dan siap berubah. Selanjutnya penelitian Bishop (2001: 227) menyatakan bahwa pimpinan pada tingkat puncak memfasilitasi kemampuan untuk perubahan dalam tingkatan mendukung serta mengembangkan kemampuan untuk perubahan. Dari hasil penelitian tersebut menjelaskan bahwa semakin kuat kepemimpinan seseorang dalam melakukan tindakan untuk perubahan organisasi, maka akan semakin tinggi tingkat tercapainya perubahan organisasi, sebaliknya semakin lemah kepemimpinan seseorang 
dalam mempengaruhi dan menggerakkan orang lain untuk melakukan perubahan, maka semakin rendah pula tingkat tercapainya perubahan. Pemimpin adalah pribadi yang memiliki keterampilan teknis, khususnya dalam satu bidang, hingga ia mampu mempengaruhi orang lain untuk bersama-sama melakukan aktifitas, demi pencapaian satu atau beberapa tujuan organisasi.

Hal ini sejalan dengan kondisi Perpustakaan Perguruan Tinggi yang dinamika organisasinya sangat dinamis, dimana perpustakaan dituntut untuk bergerak cepat untuk beradaptasi dengan perkembangan teknologi dan informasi yang begitu pesat, sehingga organisasi perpustakaan membutuhkan pemimpin yang memiliki visi kepemimpinan yang visioner. Ketika visi kepemimpinan yang diterapkan lamban maka, perpustakaan akan tertinggal jauh dengan penyedia informasi lainnya. Hal ini dapat mengancam eksistensi perpustakaan perguruan tinggi dalam menyokong informasi bagi civitas akademika di perguruan tinggi.

Posisi kepemimpinan akan sangat menentukan arah organisasi, dimana kekuatan kepemimpinan yang dapat menjaga keseimbangan perbedaan yang ada pada setiap individu, sehingga pencapaian visi, misi, dan tujuan perpustakaan bisa diwujudkan secara efektif dan efisien.

Davis (1972) dalam Harbani (2013) menyatakan bahwa, tanpa adanya kepemimpinan kuat dalam suatu organisasi, maka hanya akan menjadikan kumpulan orang-orang dan mesinmesin yang tidak teratur dan kacau balau. Hal ini dikarenakan kepemimpinan tidak hanya sekedar melakukan apa yang benar menurut diri sendiri pimpinan tersebut. Namun, menurut Reynolds (1996: 14) kepemimpinan mencakup kekuatan untuk membuat orang-orang lain mengerjakan apa yang benar menurut kemauan mereka sendiri.

Dalam mewujudkan terlaksananya tugas dan tanggungjawab Perpustakaan perguruan tinggi, gaya kepemimpinan transformasional bisa dikaji sebagai pendekatan baru dalam menentukan gaya kepemimpinan yang tepat di Perpustakaan perguruan tinggi. Menurut Bertocci (2009: 46) gaya kepemimpinan transformasional merupakan gaya kepemimpinan yang dimana seorang pimpinannya memiliki kemampuan untuk menginspirasi dan memotivasi orang lain untuk mencapai hasil melebihi harapan.

Dengan demikian, pembahasan dalam penelitiaan ini difokuskan pada kajian tentang bagaimana penerapan gaya kepemimpinan transformasional di Perpustakaan perguruan tinggi di era digital. Tulisan ini akan dijadikan sebagai bahan analisis utama dalam mengolaborasikan ketepatan gaya kepemimpinan transformasional untuk diterapkan di Perpustakaan perguruan tinggi agar perpustakaan mampu melakukan ekslerasi dalam menghadapi tuntutan pengguna akan keterbukaan informasi. Selain itu, analisis ini juga didukung dengan literatur berupa buku, jurnal, maupun sumber rujukan lain yang relavan. Pada akhirnya menjadi role model, mengingat selama ini kajian yang fokus pada pada pembahasan tentang gaya kepemimpinan di perpustakaan secara keseluruhan masih sangat minim dilakukan.

\section{B. LANDASAN TEORI}

1. Kepemimpinan dan Gaya Kepemimpinan

a. Kepemimpinan

Istilah kepemimpinan dari segi bahasa menurut Veithzal Rivai (2010: 6) adalah leadership yang berasal dari kata leader. Kata leader muncul pada tahun 1300-an, sedangkan kata leadership muncul pada tahun 1700-an. Teori dan model kepemimpinan ini kemudian didasarkan pada 4 pendekatan, yaitu teori sifat, teori kepribadian perilaku, teori kepemimpinan situasional, dan pendekatan terbaru kepemimpinan.

Beragam definisi dan konsep kepemimpinan yang ditemukan dalam berbagai bahan pustaka, yang masing-masing berbeda dalam penekanan arti. Daff (2005: 5) mendefinisikan kepemimpinan 
(leadership) adalah suatu pengaruh yang berhubungan antara para pemimpin dan pengikut (followers). Kepemimpinan menurut Andrew (2006:4) adalah kekuatan dinamis penting yang memotivasi dan mengkoordinasikan organisasi dalam rangka mencapai tujuan. Adapun Terry (2015:15) mengartikan kepemimpinan, adalah,"Leadership is the activity of influencing people to strive willingly for mutual objectives".

Merujuk dari beberapa pengertian mengenai kepemimpinan menurut beberapa ahli di atas, maka dapat disimpulkan bahwa kepemimpinan merupakan suatu proses atau suatu keterampilan seseorang dalam mempengaruhi orang lain guna mendapatkan satu misi dan arah yang sama dalam mencapai sebuah tujuan organisasi.

Kepemimpinan apabila dilihat dari sudut pandang pengaruh, Ken Blanchard yang dikutip oleh Caroselli (2000: 9) menyatakan bahwa kunci untuk kepemimpinan hari ini adalah "pengaruh" bukan "kekuasaan". Selain itu, ia juga mengatakan bahwa, para pemimpin tahu bagaimana mempengaruhi orang-orang, dan membujuk mereka untuk suatu tuntutan pekerjaan yang tinggi. Fungsi kepemimpinan menurut Andre (2010: 33-35) adalah sebagai berikut:

1) Fungsi intruksi

Pemimpin mampu bersifat komunikasi satu arah, yaitu bisa menjadi komunikator, menggerakan dan memotivasi orang lain agar mau melaksanakan perintah secara efektif.

\section{2) Fungsi konsultasi}

Pemimpin mampu bersifat komunikasi dua arah, yaitu pemimpin mampu bersikap sebagai konsultatif yang mampu menerima masukan dari orang lain, dan menginstruksikan hasil keputusan yang diambil sehingga memperoleh dukungan dari orang lain atas keputusan yang diambil.

3) Fungsi partisipasi

Pemimpin mampu mengaktifkan orang lain baik dalam pengambilan keputusannya dan pelaksanaannya secara terkendali dan terarah sehingga tercipta adanya kerjasama.

4) Fungsi delegasi

Pemimpin mampu memilih dan berbagi limpahan wewenang kepada orang lain yang dipercaya mampu menjalankan wewenang tersebut, dan memiliki persamaan dalam hal prinsip, persepsi, dan aspirasi.

5) Fungsi pengendalian

Pemimpin mampu mengatur aktivitas anggotanya dengan berperan sebagai pembimbing, pengarah, pengoordinir, dan pengawas sehingga dapat tercapainya tujuan bersama.

b. Gaya Kepemimpinan

Gaya artinya sikap, gerakan, tingkah laku, sikap yang elok, gerak gerik yang bagus, kekuatan, kesanggupan untuk berbuat baik. Gaya kepemimpinan merupakan perilaku dan strategi sebagai hasil kombinasi dari falsafah, keterampilan, sifat, sikap, yang sering diterapkan seorang pemimpin ketika ia mencoba mempengaruhi segala situasi. Menurut Rivai (2010: 42) gaya kepemimpinan merupakan dasar dalam pengklasifikasian tipe kepemimpinan. Hal ini dikarenakan gaya kepemimpinan memiliki tiga pola dasar, yaitu yang mementingkan pola pelaksanaan tugas, yang mementingkan hubungan kerja sama, dan yang mementingkan hasil yang dicapai.

Pengertian pemimpin menurut Fairchild dalam Kartono (2010: 38-39) pemimpin adalah seseorang yang memimpin dengan jalan memprakarsai tingkah laku sosial dengan mengatur, mengarahkan, mengorganisir atau mengontrol melalui upaya atau usaha dari orang lain, atau melalui prestise, kekuasaan atau posisi yang dimiliknya. Pemimpin tidak dapat terlepas dari adanya kepemimpinan dalam organisasi. Sesuai dengan pernyataan dari Siagian (1989: 25) kepemimpinan adalah kemampuan mempengaruhi perilaku manusia dan kemampuan mengendalikan 
orang-orang untuk agar perilaku mereka sesuai dengan perilaku yang diinginkan pemimpin organisasi. Dalam sebuah kepemimpinan organisasi berhasil tidaknya pencapaian tujuan organisasi dipengaruhi oleh gaya kepemimpinan diterapkan oleh setiap pemimpin. Gaya kepemimpinan menurut Kumaran (2012: 78) adalah sebagai berikut:

"Style is the way in which a leader acts. It is the way in which the leader behaves while motivating, influencing, and accomplishing. Style can either be physiological as in body language, voice, eye contact, and words used, or characteristic as in showing humility, or intellective as in being intelligent or an intellectual."

Adapun gaya kepemimpinan menurut Davis dan Newstrom (2015: 67) gaya kepemimpinan pada dasarnya mengandung pengertian sebagai suatu perwujudan tingkah laku dari seorang pemimpin, yang menyangkut kemampuannya dalam memimpin. Dengan demikian, dapat disimpulkan bahwa gaya kepemimpinan merupakan kemampuan mengendalikan atau mempengaruhi orang lain atau bawahannya untuk mendapatkan suatu tujuan yang diinginkan.

Gaya kepemimpinan apabila dilihat berdasarkan sudut pandang berbagi kekuasaan menurut Wirawan (2013: 384) adalah sebagai berikut:

Tabel. 1 Gaya Kepemimpinan

\begin{tabular}{|c|c|c|}
\hline $\begin{array}{c}\text { Gaya } \\
\text { Kepemimpinan }\end{array}$ & Keunggulan & Kelemahan \\
\hline Otokratik & $\begin{array}{l}\text { 1. Cocok digunakan untuk } \\
\text { para pengikut } \\
\text { berkualitas rendah, } \\
\text { malas, biang kerok, tak } \\
\text { mau melaksanakan } \\
\text { perintah. } \\
\text { 2. Untuk situasi darurat, } \\
\text { situasi tidak stabil, } \\
\text { konflik destruktif, dan } \\
\text { memerlukan pembuatan } \\
\text { keputusan cepat. } \\
\text { 3. Jika dipergunakan } \\
\text { dengan kompensasi, } \\
\text { dan lingkungan keria }\end{array}$ & $\begin{array}{l}\text { 1. Jika pemimpin } \\
\text { tidak bijak dapat } \\
\text { melanggar hak } \\
\text { asasi para } \\
\text { pengikut. } \\
\text { 2. Berakibat } \\
\text { kepuasan kerja } \\
\text { pengikut } \\
\text { rendah. } \\
\text { 3. Menimbulkan } \\
\text { stress kerja para } \\
\text { pengikut. } \\
\text { 4. Pengikut dapat } \\
\text { menjadi pasif. }\end{array}$ \\
\hline
\end{tabular}

\begin{tabular}{|c|c|c|}
\hline & $\begin{array}{l}\text { baik dapat } \\
\text { meningkatkan kinerja } \\
\text { para pengikutnya. }\end{array}$ & $\begin{array}{l}\text { masa bodoh, } \\
\text { dan yes man. } \\
\text { 5. Tidak ada upaya } \\
\text { memimpin untuk } \\
\text { memberdayaka } \\
\mathrm{n} \text { para } \\
\text { pengikutnya. } \\
\text { 6. Jika } \\
\text { dipergunakan } \\
\text { secara tidak } \\
\text { terukur dapat } \\
\text { menurunkan } \\
\text { kinerja para } \\
\text { pengikut. }\end{array}$ \\
\hline Paternalistik & $\begin{array}{l}\text { 1.Cocok untuk organisasi } \\
\text { dengan hubungan kerja } \\
\text { mentor dan protégé: } \\
\text { lembaga pendidikan, } \\
\text { pesantren, organisasi } \\
\text { teknologi tinggi. } \\
\text { 2.Dalam sistem sosial } \\
\text { yang menggunakan } \\
\text { kepemimpinan } \\
\text { karismatik dan } \\
\text { kekuasaan keahlian. }\end{array}$ & $\begin{array}{l}\text { 1. Jika pemimpin } \\
\text { terlalu dominan } \\
\text { dapat } \\
\text { menimbulkan } \\
\text { ewuh pakewuh, } \\
\text { yes men dan } \\
\text { rendahnya } \\
\text { kreativitas dan } \\
\text { inovasi para } \\
\text { pengikutnya. } \\
\text { 2. Pemimpin } \\
\text { menganggap } \\
\text { para pengikut } \\
\text { sebagai anak- } \\
\text { anak yang harus } \\
\text { selalu dibimbing } \\
\text { dan da diberi } \\
\text { petunjuk. } \\
\text { 3. Para pengikut } \\
\text { dapat } \\
\text { menganggap } \\
\text { pemimpin can } \\
\text { do no wrong. }\end{array}$ \\
\hline Demokratik & $\begin{array}{l}\text { 1.Cocok untuk situasi } \\
\text { normal } \\
\text { 2.Menciptakan tim kerja } \\
\text { tinggi } \\
\text { 3.Menghasilkan kepuasan } \\
\text { kerja bagi para pengikut } \\
\text { tinggi } \\
\text { 4. Jika para pengikut } \\
\text { berkualitas } \\
\text { menghasilkan kinerja } \\
\text { tinggi }\end{array}$ & $\begin{array}{l}\text { 1. Memerlukan } \\
\text { kualitas pengikut } \\
\text { tinggi } \\
\text { 2. Jika pengikut } \\
\text { berkualitas dapat } \\
\text { menimbulkan } \\
\text { anarkhis } \\
\text { 3. Memerlukan } \\
\text { peraturan yang } \\
\text { mengatur hak } \\
\text { dan kewajiban } \\
\text { pemimpin dan } \\
\text { pengikut serta } \\
\text { bagaimana } \\
\text { berinteraksi satu } \\
\text { sama lain } \\
\text { 4. Pemimpin dan } \\
\text { pengikut harus } \\
\text { memahami dan } \\
\text { menerapkan } \\
\text { prinsip-prinsip } \\
\text { demokratis, jika } \\
\text { tidak akan terjadi } \\
\text { anarkhis. }\end{array}$ \\
\hline Pemi & 1. Cocok & 1. Tidak \\
\hline
\end{tabular}




\begin{tabular}{|c|c|c|}
\hline Terima Beres & $\begin{array}{l}\text { pengikut dengan } \\
\text { kemampuan dan } \\
\text { kompetensi tinggi. } \\
\text { 2. Memberdayakan } \\
\text { pengikut. } \\
\text { 3. Meningkatkan motivasi } \\
\text { dan kepuasan kerja. } \\
\text { 4. Meningkatkan } \\
\text { kreativitas dan inovasi } \\
\text { pengikut. merancang, } \\
\text { 5. Otomasi dan } \\
\text { melaksanakan, jusing } \\
\text { mengevaluasi aktivitas. } \\
\text { 6. Meningkatkan jinerja } \\
\text { penqikut dan organisasi. }\end{array}$ & $\begin{array}{l}\text { untuk para } \\
\text { pengikut dengan } \\
\text { kemampuan } \\
\text { dan } \\
\text { kematangan } \\
\text { kerja rendah. } \\
\text { 2. Jika pemimpin } \\
\text { lemah, rentan } \\
\text { akan terjadi } \\
\text { penyalagunaan } \\
\text { oleh pengikut. }\end{array}$ \\
\hline
\end{tabular}

c. Gaya Kepemimpinan Transormasional

Menurut Veithzal Rivai (2010: 10) pemimpin Transformasional, merupakan pemimpin yang memberikan pertimbangan dan rangsangan intelektual yang diindividualkan, dan yang memiliki kharisma. Kepemimpinan transformasional (Transformational Leadership) merupakan hasil suatu perkembangan pemikiran beberapa teoritis kepemimpinan. Diawali oleh pemikiran James MacGregor Burns pada tahun 1979 yang menggunakan istilah Transforming Leadership (Kepemimpinan Mentransformasi) kemudian dikembangkan oleh Benard M.Bass pada tahun 1985 dalam bukunya yang berjudul Leadership and Performance Beyond Expectation yang menggunakan istilah Transformational Leadership (kepemimpinan transformasional) yang menurut pengakuannya terinspirasi oleh pemikiran Burns. Semenjak Bass, istilah Transformational Leadership merupakan istilah baku dalam ilmu kepemimpinan. Dalam ulusan Wirawan (2013: 138139) konsep kepemimpinan Transformasional dimulai oleh Burns (1979) dalam bukunya yang berjudul Leadership. Dalam buku tersebut ia menggunakan istilah kepemimpinan mentransformasi (Transforming Leadership) yang diformulasikan-Nya sebagai berikut:

1) Antara pemimpin dan pengikut mempunyai tujuan bersama yang melukiskan nilai-nilai, motivasi, keinginan, kebutuhan, aspirasi, dan harapan mereka.
2) Walaupun pemimpin dan pengikut memiliki tujuan bersama, akan tetapi tingkat level dan potensi mereka untuk mencapai tujuan tersebut berbeda.

3) Kepemimpinan mentransformasi berusaha mengembangkan system yang sedang berlangsung dengan mengemukakan visi yang mendorong berkembangnya masyarakat baru.

4) Kepemimpinan mentransformasi akhirnya mengajarkan para pengikut tentang bagaimana menjadi pemimpin dan melaksanakan peran aktif dalam perubahan.

5) Menurut Burns tingkat yang tertinggi dari kepemimpinan mentransformasi adalah terciptanya nilai-nilai akhir yang meliputi keadilan, kebebasan, kemerdekaan, persamaan dan persaudaraan.

Istilah kepemimpinan transformasional selanjutnya dikembangkan oleh Benard M.Bass (1985). Menurut Bass, Istilah Kepemimpinan Transformasional merupakan upaya pemimpin mentransformasi para pengikut dari suatu tingkat kebutuhan rendah hierarki kebutuhan ke tingkat kebutuhan lainnya yang lebih tinggi menurut teori motivasi Abraham Maslow. Bass mengemukakan pemimpin transformasional memiliki kemampuan memimpin yang didasarkan pada tiga karakteristik kepribadian berupa; Charisma, Individual attention dan Intellectual Stimulation. Charisma atau karisma digambarkan sebagai pemimpin yang menanamkan rasa nilaii, rasa hormat, dan kebanggaan dan mengartikulasikan visi. Oleh Bertocci (2009: 49-50) individual attention digambarkan sebagai pemimpin yang memperhatikan kebutuhan orang lain/pengikut secara individu sehingga menumbuhkan secara personal dan professional. Kemudian intellectual stimulation digambarkan sebagai pemimpin yang ikut membantu mmeikirkan jalan keluar atas suatu permasalahan atau suatu situasi kondisi tertentu 
dan mendorong pengikutnya untuk menjadi lebih kreatif.

Bernard M. Bass dan B.J Alvino (1990) mendefenisikan kepemimpinan transformasional dengan menggunakan istilah 4 I, yaitu:

1) Individual consideration (perhatian individu). Pemimpin mengembangkan para pengikut dengan menciptakan lingkungan dan iklim organisasi yang mendukung.

2) Intellectual stimulation (stimulasi intelektual). Pemimpin menstimulasi para pengikut agar kreatif dan inovatif.

3) Inspirational motivation

(motivasi

inspirational). Pemimpin menciptakan gambaran yang jelas mengenai keadaan masa yang akan dating (visi) yang secara optimis dapat dicapai dan mendorong para pengikut untuk meningkatkan harapan dan mengikatkan harapan dan mengikatkan diri kepada visi tersebut.

4) Idealized influence (pengaruh teridealisasi). Pemimpin bertindak sebagai panutan (role model).

\section{PENERAPAN KONSEP KEPEMIMPINAN TRANSFORMASIONAL DI PERPUSTAKAAN PERGURUAN TINGGI}

Menurut Kumaran (2012: 87) kepemimpinan transformasional dibutuhkan pada era saat ini karena perubahan yang terjadi pada lingkungan kerja berlangsung secara konstan dan pemimpin transformasional dianggap sebagai pilihan tepat untuk memimpin sebuah organisasi melewati perubahan-perubahan dari internal maupun eksternal organisasi. Berangkat pada pandangan ini kepemimpinan transformasional relavan untuk diterapkan pada organisasi yang fokus utama kerjanya mengurus hal-hal yang bersifat dinamis. Merujuk pada fungsi perpustakaan perguruan tinggi menurut Sulistyo-Basuki (1993: 27) sebagai sarana simpan karya manusia, informasi, rekreasi, pendidikan, dan kultural. Definisi ini menegaskan posisi perpustakaan perguruan tinggiyang fokus kerjanya menyangkut hal-hal yang sangat bersifat dinamis.

Kepemimpinan transformasinal merupakan gaya kepemimpinan yang mengutamakan pemberian kesempatan dan atau dorongan semua unsur yang ada di organisasi untuk bekerja di atas sistem nilai yang luhur, bersedia tanpa paksaan, berpartisipasi secara optimal dalam rangka mencapai tujuan organisasi. Pendapat di atas dipertegas lagi dalam definisi yang dikemukan oleh M. Bass dan B.J. Avolio (1990) tekannya kepemimpinan tranformasioanl adalah pada pemberian perhatian, stimulasi intelektual, motivasi inspirasional, dan pengaruh teridialisasi. Walaupun dari definisi ini poin demokratis tidak menjadi satu poin tersendiri melainkan masuk pada setiap poin yang diungkapkan.

Poin demokratis juga masuk dalam karekteristik kepemimpinan transformasional seperti yang diungkapkan dalam penelitiaan Tichy dan Devanna yang mengemukakan karakteristik pemimpin transformasional yaitu; (a) mengidentifikasi diri sebagai agen perubahan; (b) individu pemberani (c) mereka percaya pada orang (d) mereka adalah penarik nilai (e) mereka pembelajar sepanjang hayat (f) mereka mempunyai kemampuan berurusan dengan kompleksitas, ambiguitas dan ketidakpastian. (g) mereka visioner.

Dari keseluruhan pandangan di atas menegaskan bahwa kepemimpinan tranformasional bisa mengakomidir setiap perbedaan yang ada di dalam organisasi. Hal ini sejalan dengan apa yang disampaikan oleh Kumaran bahwa gaya kepemimpinan yang tepat untuk diterapkan di perpustakaan adalah gaya kepemimpinan yang berfokus pada etnis dan imigran minoritas yang berfokus pada ras seperti perbedaan latar belakang budaya. Kumaran melihat dengan adannya gaya yang demikian memberikan peluang bagi pemimpin perpustakaan untuk mengatasi adanya kemungkinan perpaduan budaya sehingga pustakawan imigran bisa mengeksplorasi kemampuan dan potensi yang ada pada dirinya. 
Dengan penerapan gaya kepemimpinan transformasional, pada akhirnya akan menyelesaikan permasalahan kepemimpinan yang terjadi di perpustakaan yang sering dianggap sebagai tempat pembuangan orang-orang yang tidak memiliki kompetensi yang memadai. Gaya kepemimpinan tranformasional memberi ruang pada setiap pemimpinan di perpustakaan untuk bisa mengadopsinya untuk dijadikan sebagai alat dalam penyatuan visi, misi, dan pencapain tujuan organisasi.

\section{KESIMPULAN}

Melihat kondisi perpustakaan perguruan tinggiyang tugas dan tanggungjawabnya mengurus hal-hal yang sangat dinamis, serta kondisi kelembagaan perpustakaan perguruan tinggiyang puncuk pimpinannya sering disi oleh orang-orang non keilmuan perpustakaan maka penerapan gaya kepemimpinan transformasional sangatlah tepat. Karena pimpinan dengan mempelejari gaya kepemimpinan dapat mengarahkan sumber daya manusia yang ada di dalamnnya untuk mewujudkan visi, misi, dan tujuan organisasi. Pada akhirnya membuat eksistensi perpustakaan perguruan tinggi sebagai lembaga yang bertanggungjawab dalam penyediaan informasi di perguruan tinggi bisa beradaptasi dengan arus informasi dan teknologi yang berkembang begitu cepat, sehingga pada akhirnya perkembangan teknologi dan informasi dapat bermakna positif dalam keberlangsungan roda perpustakaan di perguruan tinggi.

\section{DAFTAR PUSTAKA}

Rivai, Veithzal, dan Deddy Mulyadi. Kepemimpinan dan Perilaku Organisasi. (Jakarta: Rajawali Pers, 2010)

Terry dalam Irham Fahmi, Manajemen Kepemimpinan: Teori dan Aplikasi (Bandung: Penerbit Alfabeta, 2013)

Sutarto, Dasar-dasar Kepemimpinan Administrasi, (Yogyakarta: Gadjah Mada University Press, 2012)
Caroselli, Marcelene, Leadership Skill for Manager (NewYork: McGraw-Hill, 2000)

Maha Kumaran, Leadership in Libraries: Of Focus Minority Librarian, (Oxford: Chandos Publishing, 2012)

Davis dan Newstrom dalam Ilmi Usrotin Choiriyah, "Gaya Kepemimpinan dan Kinerja

Pegawai (Dinas Sosial Kabupaten Malang)", Jurnal Kebijakan \& Manajemen Publik (JKMP), Vol 3 No.1 Maret 2015)

Wirawan, Kepemimpinan, (Jakarta: PT. Raja Grafindo Persada, 2013)

Sutarto, Dasar-dasar Kepemimpinan Administrasi, (Yogyakarta: Gadjah Mada University Press, 2012)

Sulistyo-Basuki. Pengantar Ilmu Perpustakaan, (Jakarta: Gramedia Pustaka Utama, 1993) Richard Daff, Management (Chicago: The Dryden Press, 1988)

Bishop, Charles H Jr., Making Change Happen one person at a time: assessing change within your organization (New York: AMACOM, 2001)

Pasolong Harbani, Kepemimpinan Birokrasi (Bandung: Alfabet, 2013)

Joe Reynolds, Kepemimpinan Garis Depan: Menemukan, Mengembangkan, Menjalankan Potensi Anda (Yogyakarta: Aditya Media, 1996)

Daff, Richard L., The Leadership Experience (Canada: Thomson, 2005)

David I Bertocci, Leadership and Organication, (United Kingdom: University Press of America, 2009)

Veithzal Rivai dan Deddy Mulyadi, Kepemimpinan dan Perilaku Organisasi, (Jakarta: Rajawali Pers, 2010)

Andrew J. Dubrin, The Complete Ideal's Guides: Leadership, -Ed.2. (Jakarta: Prenada Media, 2006) Richard dan Eagel dalam Gary Yukl, Keoemimpinan Dalam Organisasi (Jakarta: Indeks, 2010)

Terry dalam Irham Fahmi, Manajemen Kepemimpinan: Teori dan Aplikasi (Bandung: Penerbit Alfabeta, 2013)

Sutarto, Dasar-dasar Kepemimpinan Administrasi, (Yogyakarta: Gadjah Mada University Press, 2012) Caroselli, Marcelene, Leadership Skill for Manager (NewYork: McGraw-Hill, 2000) 